\title{
Green First Approach for Wet Weather Programs
}

\author{
Uzair M. (Sam) Shamsi
}

Jacobs Engineering Group, Pittsburgh, Pennsylvania.

\begin{abstract}
Many United States and Canadian cities have recently started to initiate combined sewer overflow (CSO) and sanitary sewer overflow (SSO) control projects to comply with their regulatory mandates (permits and consent decrees). The capital costs of these projects are estimated to be in hundreds of millions of dollars. Both conventional gray and new green infrastructure solutions are generally required but some communities are more interested in a green first approach that requires realizing the full potential of green solutions before committing to gray solutions. This paper suggests that green infrastructure is not a panacea and green first does not mean green only. Comparing the life cycle costs and hydraulic performance of green and gray solutions is essential in the justification of a green first approach. A good green first approach should maximize the strengths and minimize the limitations of both the gray and green solutions. This paper compares green and gray infrastructure and discusses green vs gray cost and performance comparison approaches and tools. Real world examples are included and relevant software tools and models are summarized.
\end{abstract}

\section{Introduction}

Many United States and Canadian cities are planning, designing or constructing multi-million or multi-billion dollar wet weather control projects in order to comply with their discharge permits and consent decrees. Different types of infrastructure solutions are being considered. Interest in conventional solutions is declining whereas new sustainable solutions are gaining in popularity. This section provides definitions, examples and comparisons of infrastructure types relevant to wet weather projects.

As shown in Figure 1 and as described in the following subsections, there are four types of infrastructure that have a role in solving wet weather problems: blue infrastructure, gray infrastructure, green infrastructure and hybrid infrastructure (combinations of two or more of the preceding types). Table 1 lists common blue, gray, and green infrastructure technologies.

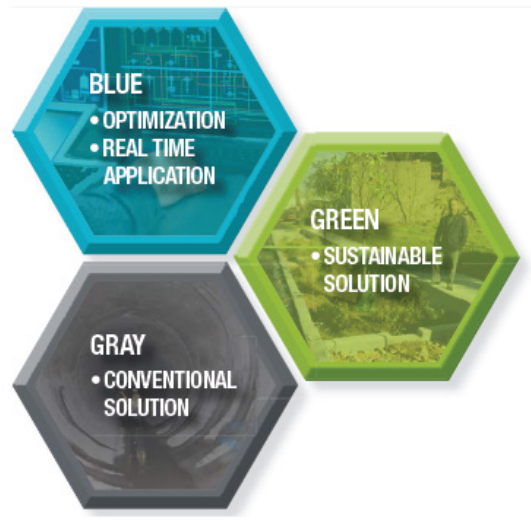

Figure 1 Three types of wet weather infrastructure.
Table 1 Summary of gray and green infrastructures.

\begin{tabular}{lll}
\hline \multicolumn{1}{c}{ Blue Infrastructure } & \multicolumn{1}{c}{ Gray Infrastructure } & \multicolumn{1}{c}{ Green Infrastructure } \\
\hline Real time control (RTC) & Conveyance (sewers, manholes and pumps) & Rain barrel \\
SCADA system & Sewer separation & Rain garden or bioretention \\
& & cell \\
Flow and level sensors & Storage tank & Green roof \\
Inflatable dams & Storage tunnel & Porous pavement \\
Automated sluice gates & Screening and disinfection & Bioswale \\
& Vortex separation & Infiltration basin or trench \\
& Retention-treatment basin & Constructed wetland \\
& High rate clarification & Vegetated filter strip \\
& Satellite treatment & Planter \\
\hline
\end{tabular}

\subsection{Blue Infrastructure}

Blue infrastructure is also referred to as smart infrastructure because, by installing flow and level sensors at strategic locations within the sewer system, it can make existing sewer pipes smart. The objective of blue infrastructure is to maximize the use of existing gray infrastructure for storing wet weather flow. It is, therefore, also referred to as wet weather optimization. Blue infrastructure is based on the application of real time control (RTC) using a supervisory control and data acquisition (SCADA) system to optimize system storage by better managing the capacity of the system for conveyance and treatment. Blue infrastructure examples include inflatable dams and sluice gates installed at strategic locations in the collection and interceptor systems. This approach does not work everywhere so extensive RTC modeling is required to assess the feasibility and effectiveness. Sewer systems with large flat sewers are good candidates; systems with

Shamsi, Uzair M. (Sam). 2018. Green First Approach for Wet Weather Programs. Journal of Water Management Modeling 26:C439. https://doi.org/10.14796/JWMM.C439 c CHI 2018. www.chijournal.org ISSN 2292-6062. 
small steep sewers are not. An example project is included in section 4.

\subsection{Gray Infrastructure}

Gray infrastructure is defined as traditional brick, mortar or concrete construction to manage sanitary sewer, combined sewer and stormwater flow.

Gray technologies can be generally grouped into the following broad categories:

- conveyance or collection system control: gravity sewers, pump stations, hydraulic relief structures, inline storage, outfall relocation or consolidation, and regulator or diversion structure modification;

- sewer separation: separating combined sewers into sanitary sewers and storm sewers;

- storage: above ground and below ground tanks and tunnels; and

- treatment: screening and disinfection, vortex separation, retention and treatment basins, high rate clarification (sometimes called ballasted flocculation or sedimentation), and satellite sewage treatment.

\section{Gray Infrastructure Example: Storage Tunnel}

Also known as combined sewer overflow (CSO) tunnels or deep tunnels (depth $\sim 100 \mathrm{ft}, 30 \mathrm{~m}$ ), storage tunnels are large (10 ft to $30 \mathrm{ft}, 3 \mathrm{~m}$ to $9 \mathrm{~m}$, diameter) underground concrete pipes that are used to capture, store and convey large volumes of CSO or storm sewer overflow (SSO) discharge. Deep tunnels can accommodate large overflow volumes with little or no disruption to the surrounding land surface and can capture all of the smaller storms and some fraction of the larger storms. Flow from the sewer collection system is conveyed to the tunnel using shallow consolidation pipes which are constructed by intercepting existing CSO outfall pipes. The effluent is generally transported, pumped and treated at a sewage treatment plant before being discharged to the receiving waters. Projects examples and photos are provided in section 4.

\subsection{Green Infrastructure}

When green infrastructure is used for stormwater management, it is referred to as green stormwater infrastructure (GSI). GSI is defined as runoff source controls that use natural processes to reduce the volume of stormwater entering the sewer system. Variously referred to as sustainable infrastructure, low impact development (LID), or best management practices (BMP), GSI includes technologies designed to capture surface runoff using some combination of detention, infiltration and evapotranspiration (Shamsi et al. 2013). GSI is designed to capture surface runoff, close to its source, at distributed (decentralized) locations (Shamsi 2011). Rain gardens or bioretention cells, subsurface infiltration, green roofs, porous pavement and street planter boxes are common GSI examples.
Figure 2 shows a conceptual diagram of a GSI implementation at the property level (3RWW 2013). As a means of reducing the volume of stormwater runoff entering a wastewater system, and also of reducing its peak flows, GSI solutions can be applied through source controls to use infiltration, evapotranspiration or storage of stormwater runoff for beneficial uses. These approaches prevent stormwater runoff from entering a combined sewer system and reduce overflows. Using GSI, it is possible to eliminate overflows resulting from the small and more frequent rainfall events which typically account for $>90 \%$ of storm events. GSI is capable of providing significant levels of control over the course of a year through its performance with small to moderate storms (ALCOSAN 2012). GSI is not effective for larger storms because it relies on natural systems which generally act more slowly and are smaller than artificial structures. For larger storms, green-gray hybrid solutions are generally required (see section 1.4 below). Despite the sustainability benefits, some GSI solutions are not suitable in certain climates, topographies and soils.

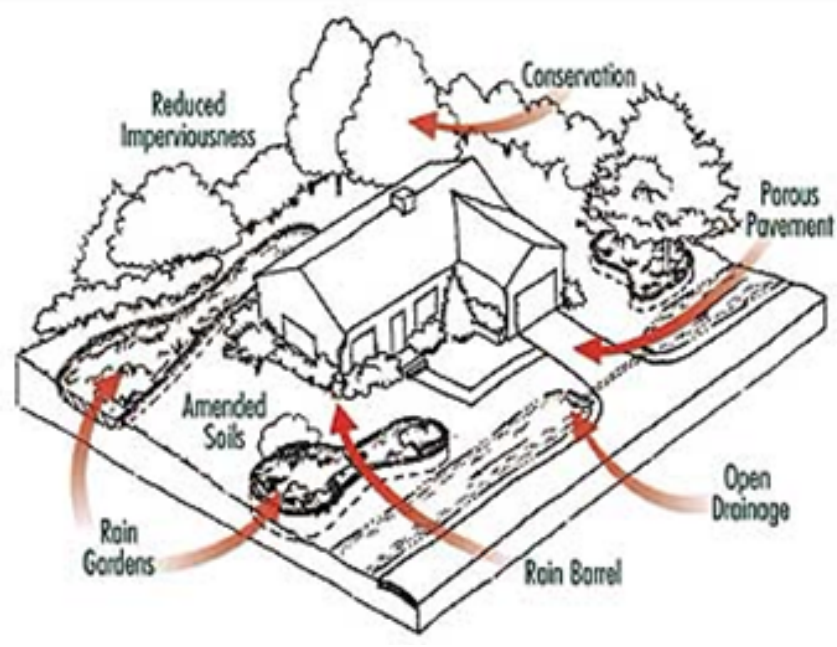

Figure 2 Green stormwater infrastructure implementation at the property level (source: 3RWW, 2013).

Recently, stormwater and wastewater utilities have started to use GSI controls as a viable means of managing stormwater runoff from new and existing developments. However, the benefits of this type of sustainable infrastructure in the reduction of sewer overflow discharges are not well understood and are often overlooked (Shamsi 2011). Most affected communities have already evaluated conventional gray infrastructure alternatives and will undoubtedly pursue the gray options as opposed to green solutions, absent the availability of GSI technical information.

\section{Green Infrastructure Example: Rain Gardens}

Rain gardens (also known as bioretention cells) are landscaping features adapted to provide onsite capture and treatment of stormwater runoff. When planned and installed correctly, they can be effective in achieving runoff reduction objectives and can improve neighbourhood aesthetics as they can be 
visually appealing stormwater management tools. For property owners who have frequently noticed standing water on their lawns, have observed soil erosion, or who need to move stormwater away from the home foundation, a rain garden may be the right solution.

Rain gardens help to manage the stormwater that falls on a property thereby preventing it from immediately entering and overwhelming the storm sewer system. They collect and hold rainwater for a brief time $(<48 \mathrm{~h})$, slowly release it through the soil, or allow plants to first absorb the water and then slowly release it back to the environment by evapotranspiration. Project examples and photos are provided in section 4.

\section{Maintenance Requirements}

Rain garden maintenance activities include pruning

(1 time/y-2 times/y), mowing (2 times/y-12 times/y), mulching (1 time/y-2 times/y), watering during drought conditions, and spot weeding during the growing season (1 time/month).

\section{Cost Estimates}

Rain garden construction cost varies from $\$ 26 \mathrm{USD} / \mathrm{ft}^{2}$ for new construction to $\$ 58 \mathrm{USD} / \mathrm{ft}^{2}$ for retrofitting with underdrain and lined units (3RWW 2013). The Three Rivers Rain Garden Alliance website provides an online rain garden design and costing tool for western Pennsylvania conditions. For example, for an impervious area of $1000 \mathrm{ft}^{2}\left(92.9 \mathrm{~m}^{2}\right)$, with design rainfall of $1 \mathrm{in}$. (2.54 $\mathrm{cm})$, sandy soil, and steep slope (8 in., $20.3 \mathrm{~cm}$, drop), the tool estimates a rain garden area of $125 \mathrm{ft}^{2}\left(11.6 \mathrm{~m}^{2}\right)$ at a cost of approximately \$428 USD (2011 dollars). The calculations are shown in Figure 3. If the soil is clay and the slope is flat $(4 \mathrm{in} ., 10.2 \mathrm{~cm}$, drop), the tool estimates a rain garden area of $500 \mathrm{ft}^{2}\left(46.5 \mathrm{~m}^{2}\right)$ at a cost of approximately $\$ 1710$ USD.

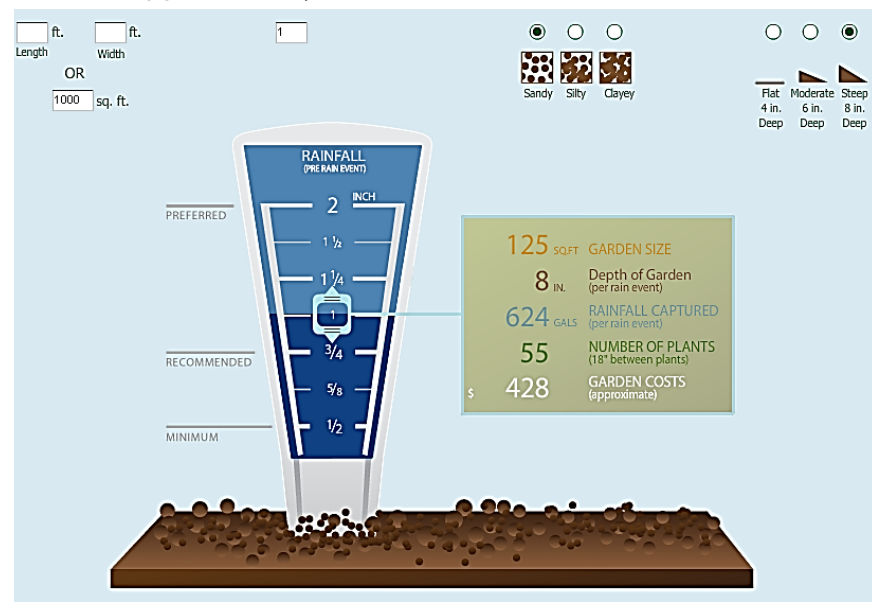

Figure 3 Online rain garden design and costing tool (source: Three Rivers Rain Garden Alliance).

\subsection{Hybrid Infrastructure}

Hybrid infrastructure is created by mixing other infrastructure types. For large and complex sewer systems, blue, gray or green infrastructure alone is usually not sufficient to meet design and cost performance criteria and thus infrastructure should be of a mixed type. For example, gray infrastructure is a necessary additional component of a wet weather plan when green and blue infrastructures are not enough.

Data from the Cleveland, Ohio gray and green hybrid wet weather program indicate that green projects cost much more to prevent each gallon of overflow than a simply designed gigantic underground storage tunnel. GSI accounts for $1.8 \%$ of total project costs and will stop about $0.5 \%$ of the total volume of overflows.

"The volume you knock off with the green infrastructure, you may be taking an $18 \mathrm{ft}(5.48 \mathrm{~m})$ diameter tunnel down to 17.5 $\mathrm{ft}(5.33 \mathrm{~m})$. At the end of the day, you're going to build an $18 \mathrm{ft}$ (5.48 m) tunnel" —Kimberly Marshall, Deputy Director of Engineering and Construction, Northeast Ohio Regional Sewer District (Moore 2015).

\section{Green vs Gray}

Over 100 years ago when combined sewers were constructed, they were thought of as a cutting edge gray infrastructure solution. Combined sewer communities are now spending billions of dollars to fix the CSO problems of those inadequate gray systems.

Six years ago, the roadside rain gardens of Ballard City (a suburb of Seattle, Washington) got media attention because they did not perform well (Seattle Magazine 2011; Stiffler 2011). Rain gardens did not drain properly and flooded frequently. Other factors included insufficient stakeholder involvement, inadequate geo-technical investigation prior to design, lack of contractor experience during construction, and the absence of underdrains.

Despite this and similar such examples, and insufficient data on the hydraulic performance and regulatory compliance of GSI solutions, some cities think that green infrastructure is a better CSO solution. People also assume that GSI can improve water quality in their rivers and streams, spur economic development, and advance their quality of life. If these cities do not want their rain gardens to look like cesspools, they should apply the lessons learned and make sure that their green infrastructure will be more sustainable than the inadequate combined sewers of the past. The last thing cities should do is spend billions of dollars to construct something that will not meet the applicable hydraulic performance criteria, and then spend even more money to fix the new problems. It behoves cities to make sure that their green infrastructure is designed, operated and maintained properly.

GSI presents both opportunities and challenges. Table 2 compares the opportunities offered and challenges faced by GSI based on environmental, social and economic factors. 
Table 2 Green stormwater infrastructure opportunities and challenges.

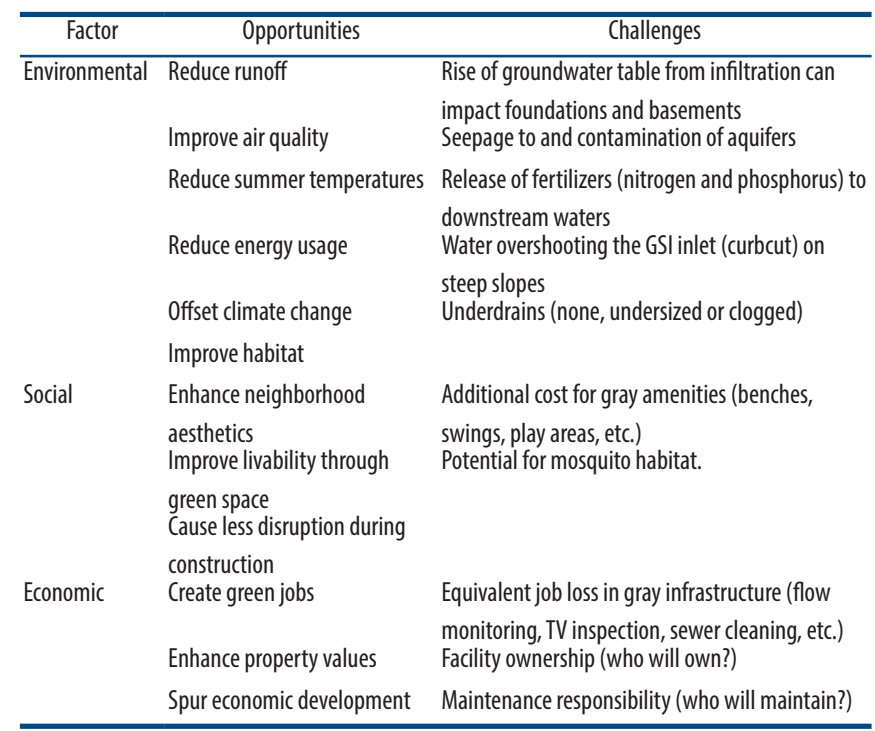

Figure 4 shows the results of Allegheny County Sanitary Authority's CSO control technology screening process (ALCOSAN 2012). Gray and green infrastructures are compared based on the following factors:

- economics;

- community;

- public health and environmental concerns;

operation and maintenance; and

- implementation and construction.

Favourable ratings are denoted by + and negative ratings by -; neutral ratings are shown as 0 . Economic factors were not used in this comparison.

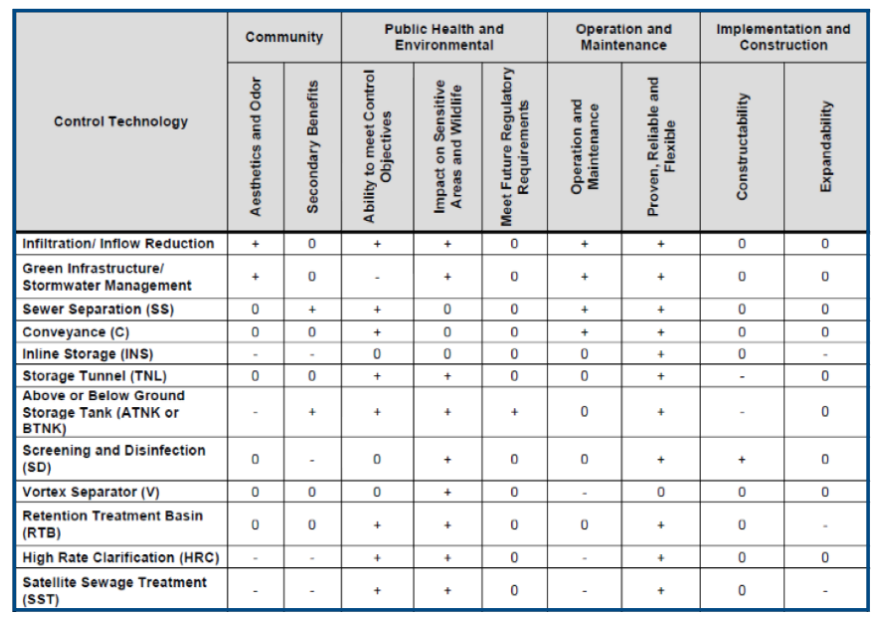

Figure 4 Comparison of gray and green infrastructures (source: ALCOSAN Wet Weather Plan, ALCOSAN 2012).

A recent Syracuse University study concluded that although GSI is relatively new, it is being widely adopted, but there are few studies in the peer reviewed literature that report and contrast the performance of different green infrastructure technologies. Despite the growing interest in GSI for stormwater management, limited information is available concerning GSI design, implementation, operation and maintenance. The Syracuse study suggests that an understanding of both the strengths and limitations of GSI is essential (Driscoll et al. 2015).

\section{Green First Approach}

Cost comparison is the most common method for assessing the economic impacts of GSI. The two basic approaches to cost analysis are to address:

- only initial capital costs; or

- life cycle or whole life costs, including planning, design, installation, operation and maintenance, replacement, and the residual value of assets.

Both approaches ignore the differences in performance between green infrastructure and gray infrastructure. As a result, they do not provide a complete basis for decision making (USEPA 2017). Life cycle cost refers to the total cost of operation over the life of an asset. Costs considered include the financial cost, which is relatively simple to calculate, and the environmental and social costs, which are more difficult to quantify (Wikipedia 2017).

Sustainability is commonly described with three P's: planet, people and prosperity. Therefore, instead of focusing solely on the direct financial (cost) impacts of a project, a triple bottom line (TBL) analysis that considers economic (cost), environmental, and social benefits will add consideration for environmental and social equity factors into the overall decision making. Using TBL analysis can result in a more holistic and presumably better decision (PWSA 2016). TBL analysis evaluates a project or policy based on its combined financial, social and environmental impacts. The financial impacts (or profits) are the life cycle (whole life) costs associated with the project. The social (or people) impacts are the effects of a project on the broader community such as the quality of life. Finally, the environmental (or planet) impacts are the effects of a project on the surrounding environment, habitat or climate. These three values together form the TBL valuation (Parker 2017).

The TBL approach is a useful method for comparing green and gray infrastructure. TBL values should be calculated objectively using a standard rating system rather than be guessed subjectively. People often confuse GSI effectiveness for stormwater management with CSO compliance. GSI may be more effective for stormwater management than for CSO compliance. Stormwater management is generally a local problem. In the context of flooding, stormwater management is intended to reduce runoff from large return period storms ( $10 \mathrm{y}$ to $100 \mathrm{y}$ ) over small drainage areas. It requires post development runoff not to exceed pre development runoff (which is why GSI is also called low impact development, LID). To the contrary, CSO management is a regional problem. It requires a substantial (e.g. $85 \%$ ) runoff volume reduction from small return period storms ( 1.5 months to 3 months) 
over large sewersheds. The focus is on the overflow from the CSO outfall rather than the runoff from properties or street flooding. It is extremely challenging for GSI alone to meet the CSO reduction requirement and a hybrid approach is generally required where gray infrastructure must do most of the work. In a CSO project where overflow volume reduction rather than flood control is the main objective, it is therefore not sufficient to say that GSI has a higher TBL value because it can reduce flooding.

Generally green, gray, and blue wet weather solutions are combined in solving wet weather problems. Recently some stakeholders and communities have become interested in a green first approach that requires maximizing the full potential of green solutions before committing to gray solutions. Green first does not mean green only. A green first approach can incorporate both green and gray infrastructure. The green first approach includes smart elements of green infrastructure in areas where it effectively replaces elements of traditional gray infrastructure at a lower cost, and also where such elements can be leveraged into community amenities that will spur economic development and improve neighbourhoods. The green first approach can be implemented by using smart green solutions which meet the following criteria:

- meet the GSI placement (BMP siting) criteria (e.g. tributary area, imperviousness, soil type, slope);

- reduce or eliminate the overflows at consent decree CSO or SSO locations;

- reduce or eliminate proposed gray infrastructure (green for gray substitution); and

- have a life-cycle cost (or TBL) less than gray infrastructure for the same level of control (e.g. \% overflow reduction or $\$ / g a l)$.

Software tools for quantifying the above criteria are described in section 5 below.

Figure 5 shows the iterative nature of the green first approach. The steps are:

1. Identify potential GSI locations using a program such as the SUSTAIN BMP Siting Tool (see subsection 5.1 below);

2. Screen the potential GSI locations using site visits, desktop studies, drone surveys, land ownership, right of way (ROW) information, community interest, and local conditions to identify GSI projects (Lennon et al. 2013);

3. Model the GSI hydraulic performance (\% capture) using modeling tools described in subsection 5.1;

4. Determine GSI life cycle cost using costing tools described in subsection 5.1;

5. Calculate the GSI TBL value using tools like Envision and Autocase (see subsections 5.4 and 5.5); hydraulic performance and life cycle cost should be included in TBL calculations;

6. Model the gray solution hydraulic performance (\% capture) using hydrologic and hydraulic $(\mathrm{H} \& \mathrm{H})$ models (e.g. SWMM); this information may be already available if a gray wet weather plan has been completed;

7. Determine the gray solution life cycle cost; this information may be already available if a gray wet weather plan has been completed;

8. Calculate the gray solution TBL value using tools like Envision and Autocase (see subsections 5.4 and 5.5); hydraulic performance and life cycle cost should be included in TBL calculations;

9. Compare the GSITBL with the gray infrastructure TBL for the same level of control (e.g. $85 \%$ CSO volume capture);

10. Implement the green solution if the GSI TBL is better than the gray solution; and

11. Add blue and gray solutions if the GSI TBL is not better than the gray solution.

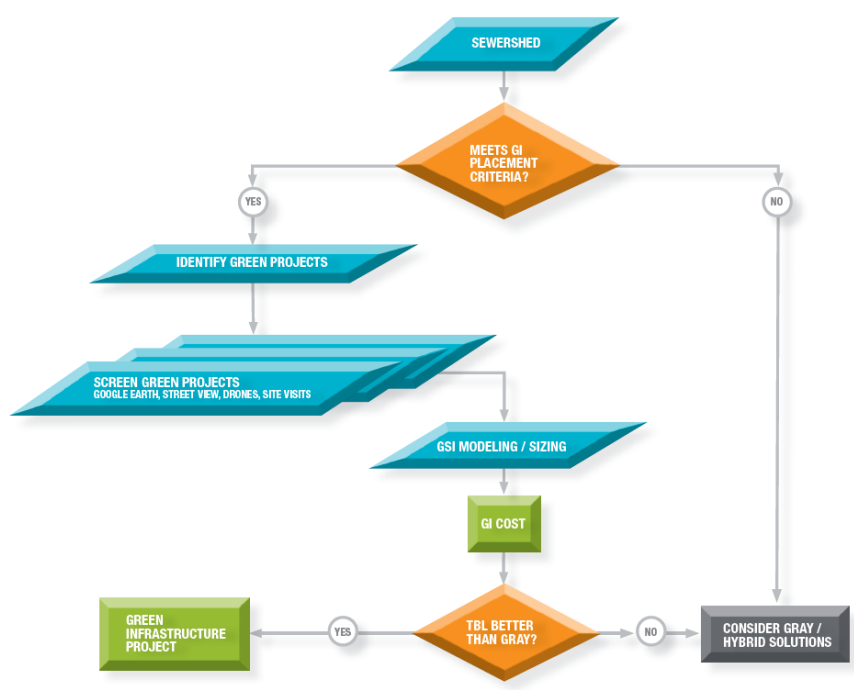

Figure 5 Green first approach flow chart.

Green projects that have a better TBL value than the corresponding gray projects qualify as green first projects. Green projects that have a lower TBL value than the corresponding gray projects do not qualify as green first projects. These latter projects can be bundled with gray storage and conveyance infrastructure to create hybrid gray-green-blue projects. Finally, gray projects can be greened by incorporating green leave-behind projects which include post-construction greening of gray project sites, such as a community park at a tunnel shaft location.

As indicated in the previous section, green stormwater infrastructure is not a panacea. Recent studies have shown that despite the growing interest in green solutions, there is limited information concerning their design, implementation, operation and performance. The GSI approach is still relatively new and, although it is being widely adopted, there are few studies in the peer reviewed literature that report and contrast the performance of different green infrastructure technologies. For example, using decades of gray infrastructure education and experience, as well 
as a vast library of handbooks, manuals and computational tools, engineers can quickly design a detention basin to reduce the CSO volume at an outfall by $85 \%$. They can confidently estimate the construction cost and prepare a maintenance manual. Unfortunately, designing green solutions to meet the same target is more challenging due to an all-round shortage of experience, cost estimation databases, and proven design tools. For best results, green solutions must be planned and designed with the same level of resources as their gray counterparts, which have received most of the planning attention in most wet weather projects.

A good green first approach should, therefore, recognize the strengths and limitations of both the gray and green solutions. Comparing the life cycle cost (capital + operation and maintenance) and hydraulic performance (overflow reduction) of green and gray solutions is essential for implementing a green first approach.

\section{Examples}

\subsection{Gray Infrastructure, Atlanta, Georgia}

Figure 6 shows an example of a CSO tunnel, from Atlanta, Georgia. This is the $8.5 \mathrm{mi}(13.7 \mathrm{~km})$ long, $24 \mathrm{ft}(8 \mathrm{~m})$ diameter West Area CSO tunnel constructed during 2004-2008. Figure 7 shows the plan and section for a tunnel section.

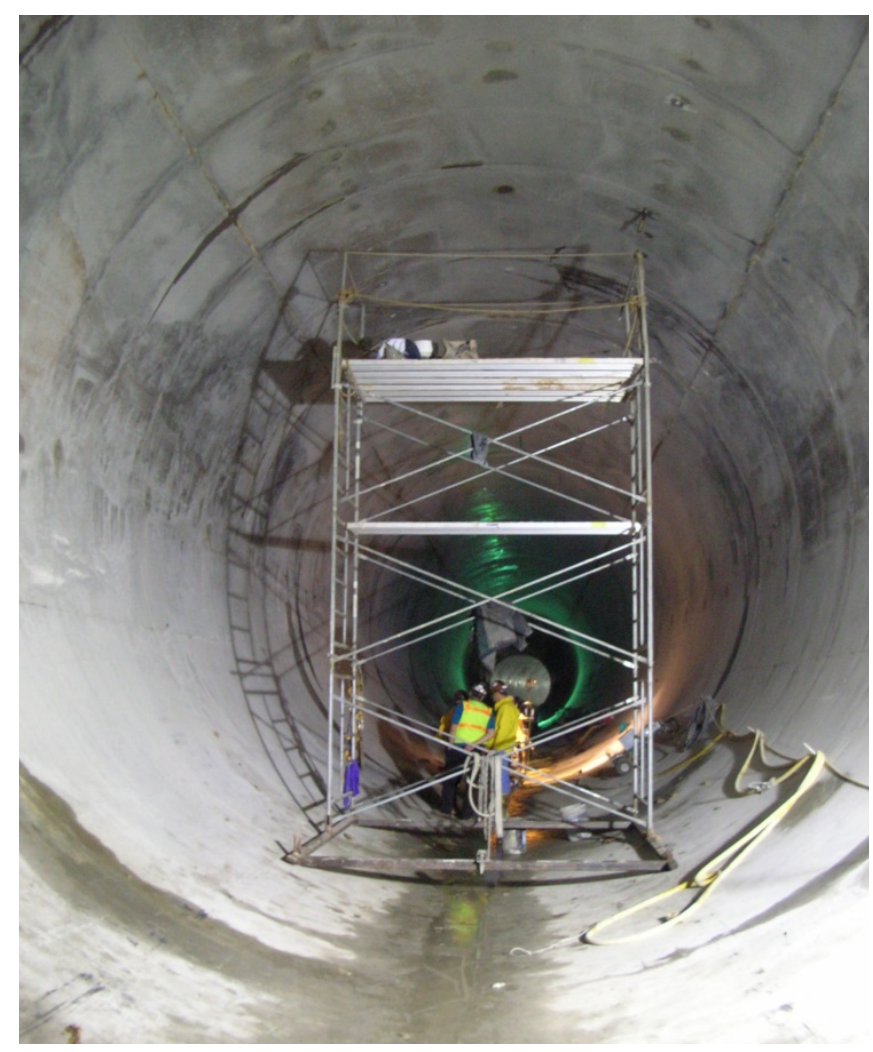

Figure 6 Storage tunnel example, Atlanta, Georgia 20042008 (photo courtesy of Jacobs Engineering Group).
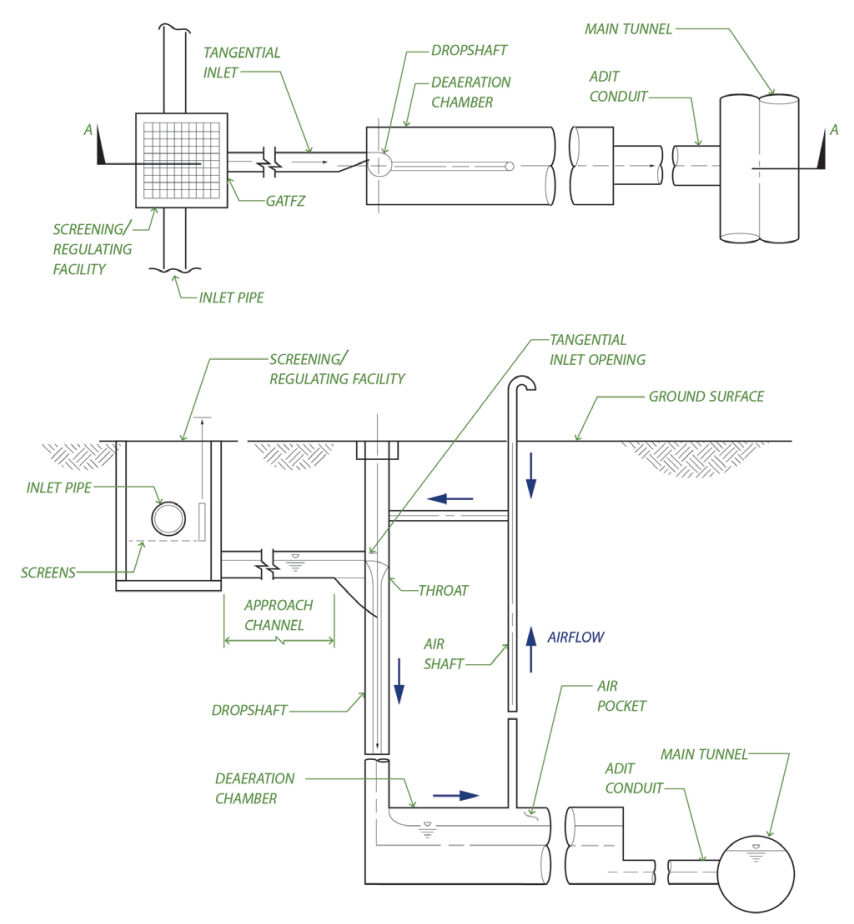

Figure 7 Storage tunnel plan and section, Atlanta, Georgia 2004-2008 (drawing courtesy of Jacobs Engineering Group).

As shown, the tunnel has properly spaced ventilation and drop shafts. It captures, stores, and conveys CSO from the Clear Creek, Tanyard and North Avenue CSO basins. It stores up to 177 MG $(670000000 \mathrm{~L})$ of overflow from a rainstorm. When the rainfall is over, the overflow is conveyed to a dedicated CSO treatment plant for pollutant removal and ultraviolet disinfection before being discharged to receiving waters (City of Atlanta 2017). Atlanta has started to include GSI elements.

\subsection{Blue Infrastructure, Cincinnati, Ohio}

Over the last two years, Metropolitan Sewer District of Greater Cincinnati (MSDGC), Ohio, has been working to develop a smarter sewer system, one that uses the existing sewer system more efficiently and effectively and is more affordable to ratepayers. For example, when it rains in one part of Cincinnati, the interceptor sewers in that location may be full, but other areas where it has not rained may have lots of available capacity. This approach allows MSDGC to store flows inside large interceptor sewers, storage tanks, and high-rate treatment facilities in different parts of the sewer system using sensors to measure flow levels and gates and valves to direct the flows. The entire system is controlled by a SCADA computer system. This helps to keep sewage in the pipes and out of the creeks.

In early 2015, MSDGC deployed its new smart sewer system in the Mill Creek basin, which covers the central portion of Hamilton County. Within the first several weeks of operation, the technology was used to store flows at a high-rate treatment facility, avoiding 1.4 MG (5 $300000 \mathrm{~L}$ ) in sewer overflows at a 
location nearly $11 \mathrm{mi}(17.7 \mathrm{~km})$ away. The cost savings result from not having to commission as many new capital projects to reduce the overflows, such as constructing larger sewers and storage tanks.

Compared to this blue infrastructure solution, gray infrastructure is more expensive and takes a long time to plan and construct. Early data shows that smarter sewers cost $\sim 0.01 / \mathrm{gal}(\$ 0.0026 / \mathrm{L})$ of overflow volume reduced, as compared to $\sim \$ 0.23 / \mathrm{gal}(\$ 0.061 / \mathrm{L})$ for green stormwater controls and $\sim \$ 0.40 /$ gal $(\$ 0.106 / L)$ for gray infrastructure (larger pipes and storage tanks).

South Bend, Indiana recently invested in a similar technology, which is projected to reduce its consent decree spending by $\sim 27 \%$ (Pica and Shamsi 2017).

\subsection{Green Infrastructure, Cincinnati, Ohio}

MSDGC is currently implementing a program to satisfy the requirements of a wet weather improvement plan (WWIP) mandated by a consent decree. The final WWIP was approved by the U.S. Environmental Protection Agency (USEPA) and the Department of Justice in 2009 and it calls for system wide improvements to address CSOs and SSOs. These improvements are to be implemented over the next $20 \mathrm{y}$ with a total estimated construction value of $\$ 1.145$ billion for Phase 1 (by December 2018) and an additional $\$ 2.0$ billion for Phase 2 projects (Shamsi et al. 2016).

MSDGC started implementing GSI solutions in 2009 as part of Project Groundwork (http://www.projectgroundwork. org). Twenty-five small GSI projects have been constructed at a cost of $\$ 67$ million, some supported by grants, in partnerships with local organizations such as schools, institutions, colleges and universities, communities and churches. These projects include a mix of source control, rain gardens, bio-swales, permeable and porous pavements, green roofs, bio-retention basins, and cisterns. Figure 8 shows an example of a rain garden from MSDGC's GSI projects.

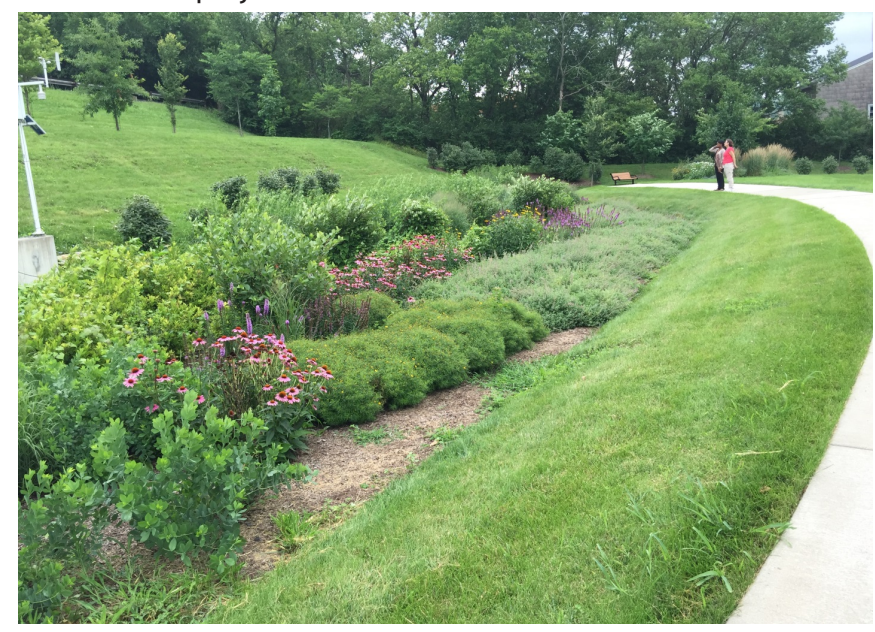

Figure 8 Rain garden example from Cincinnati, Ohio (2015).
Four projects, each with a different set of GSI elements, collected flow data from $>160$ rainfall events for each project, events that occurred before, during and after installation of the green infrastructure. Statistical analyses using the WinSLAMM program were performed to determine the runoff volume reductions achieved by GSI. Three projects were found to be $70 \%$ to $85 \%$ effective and one was $20 \%$ effective, when comparing pre- and post-construction runoffs (Pica and Shamsi 2017). Because Cincinnati includes both gray and green projects, the wet weather program can also be considered a hybrid program.

\subsection{Hybrid Infrastructure, Washington, D.C.}

Currently, DC Water (Washington, D.C.) is implementing the \$2.6 billion Clean Rivers Project (https://www.dcwater.com/ clean-rivers-project) to comply with their wet weather consent decree. The first phase is underway and involves construction of an underground tunnel system (gray infrastructure) to hold stormwater during intense storms, thus preventing most CSOs to the Anacostia River. These overflows, which on average discharge 1.5 billion gal (5.7 billion L) of diluted sewage to the Anacostia River annually, will be reduced by $98 \%$ when the tunnel system is completed in 2022. The later phases will address overflows to the Potomac River and Rock Creek. In 2014, DC Water proposed the use of a hybrid approach that will substitute GSI for some-but not all-of the massive tunnels planned to convey stormwater and sewage to the Blue Plains advanced wastewater treatment plant (Shamsi and Barron 2015).

DC Water's wet weather program has recently shifted from an all gray to a gray-green hybrid program. GSI solutions are now being implemented in the Rock Creek and Potomac River drainage areas. The existing plans for the Anacostia River tunnels remain unchanged. For Rock Creek, DC Water proposed to eliminate the planned tunnel and replace it with GSI projects costing $\$ 60$ million. Implementation will be completed by 2032 . For the Potomac River, DC Water proposed GSI projects costing $\$ 30$ million that would be completed by 2028. The GSI investment, combined with new upgrades to the wet weather treatment capacity at DC Water's Blue Plains facility, will allow the previously planned underground tunnel along the Potomac River to be reduced in size. The smaller tunnel will be completed in 2030. In addition, $\$ 10$ million will be invested to separate the combined sewer system in designated neighborhoods.

\subsection{Green First Plan, Pittsburgh, Pennsylvania}

In November 2016, Pittsburgh Water and Sewer Authority (PWSA) released a draft green first plan (PWSA 2016). The Green First Plan: A City-Wide Green Infrastructure Assessment (Draft) is the City of Pittsburgh and PWSA's plan to manage issues related to stormwater flow. The Allegheny County region experiences degraded water quality from frequent CSOs and SSOs. The draft plan examines the existing stormwater conditions in order to guide where green infrastructure will be installed to achieve the most cost-effective and beneficial results to the residents of Pittsburgh. 
The creation of the plan required extensive sewershed and hydrologic analysis, community and stakeholder outreach, and consideration of future development projects within Pittsburgh. The draft plan analyzed 13700 acres $\left(55.44 \mathrm{~km}^{2}\right)$ in the city and proposes to manage runoff from 1835 acres $\left(7.43 \mathrm{~km}^{2}\right)$ using green infrastructure over the next $20 \mathrm{y}$. The draft plan includes concept level details for six priority sewersheds where green infrastructure would provide significant benefits. The green infrastructure methods to be used in each sewershed were selected using criteria that considered factors such as cost and community impact. This approach is designed to guide the integration of stormwater management with capital improvement projects and urban planning processes.

\section{Software Tools}

This section describes computer programs for GSI mapping, modeling, planning, designing, costing, and evaluation.

\subsection{GSI Models}

GSI models quantify the cost and performance (e.g. annual CSO discharge volume) for green, gray or hybrid alternatives. Figure 9, which can be used as a model selection catalog, provides a list of common models used in the United States. It includes three types of models: spreadsheet, basic and advanced. Users can select a model that meets their specific needs and resources. The Water Environment Research Foundation (WERF) Whole Life Costing spreadsheet tool can be used to estimate the life cycle cost (capital + operation and maintenance costs) of GSI alternatives.

\begin{tabular}{|c|c|c|c|}
\hline \multirow{2}{*}{ Features } & \multicolumn{3}{|c|}{ Model Type } \\
\hline & Spreadsheet & Basic & Advanced \\
\hline Application & Quick screening and planning & Screening and planning & Planning and sizing \\
\hline Input data & Low & Medium & Extensive \\
\hline Technical expertise & Basic & Basic & Advanced \\
\hline Effort & Low & Moderate & High \\
\hline Results & Approximate & Less approximate & More accurate \\
\hline \multirow{3}{*}{$\begin{array}{c}\text { Examples } \\
\text { (Public Domain) }\end{array}$} & WERF BMP Select & EPA National SW Calculator & SWMM \\
\hline & WERF Whole Life Costing Tool & L-THIA LID & SUSTAIN \\
\hline & EPA Green LTCP-EZ & & RECARGA \\
\hline \multirow{2}{*}{$\begin{array}{l}\text { Examples } \\
\text { (Commercial) }\end{array}$} & & & WinSLAMM \\
\hline & & & $\begin{array}{c}\text { InfoSWMM SUSTAIN } \\
\text { XPDrainage }\end{array}$ \\
\hline
\end{tabular}

Figure 9 GSI models.

\subsection{SUSTAIN}

The USEPA's SUSTAIN software program provides an integrated ArcGIS based GSI mapping and modeling platform (USEPA 2013) to facilitate the selection and placement of GSI facilities at strategic locations in urban watersheds. SUSTAIN incorporates sophisticated algorithms for evaluating GSI effectiveness (Urbonas et al. 2013). For GSI planning, SUSTAIN can answer three questions:

1. Siting: Where are the best GSI locations?

2. Performance: How effective are the locations in reducing runoff and pollutants? and

3. Cost: How much will they cost?
Siting analysis is done using the BMP Siting Tool (BST) module of SUSTAIN.

In Allegheny County watersheds around Pittsburgh, Pennsylvania the BST module identified nearly 525000 potential GSI locations, including 156360 bioretention locations. Detailed SUSTAIN and BST module information is available in the co-authored SUSTAIN paper published in this journal (Shamsi et al. 2013). Note that SUSTAIN is not compatible with the latest versions of ArcGIS software.

\subsection{LEED}

Leadership in Energy and Environmental Design (LEED) is one of the most popular green building certification programs developed by the nonprofit U.S. Green Building Council in 1998. Projects pursuing LEED certification earn points across several areas that address sustainability issues. Based on the number of points achieved, a project then receives one of four LEED rating levels: certified, silver, gold and platinum. LEED-certified buildings are resource efficient. They use less water and energy and reduce greenhouse gas emissions. LEED is a rating system for buildings, not infrastructure. It is not suitable for evaluating gray or green infrastructure projects. However, a tangible benefit of green certified buildings is that they reduce the demand on stormwater infrastructure.

\subsection{Envision}

The Institute for Sustainable Infrastructure (an organization cofounded by The American Society of Civil Engineers in 2011) developed the Envision rating system to measure sustainable infrastructure projects in five categories:

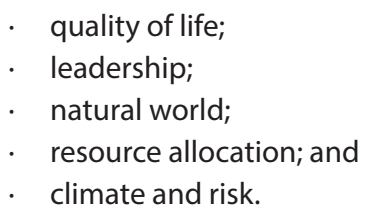

Before Envision, people had no choice but to use the LEED rating system for their GSI projects. Envision evaluates, grades, and recognizes infrastructure projects that use transformational and collaborative approaches to assess the sustainability indicators over the course of the project's life cycle.

\subsection{Autocase}

Autocase for Green Infrastructure is software from Impact Infrastructure that quantifies the TBL value of sustainable designs. It can also be used to evaluate or compare green, gray and hybrid alternatives based on the triple bottom line benefits for social, environmental and financial factors. Autocase enhances the Envision rating system, adding the capability for the Envision system to provide value-based and risk-adjusted analyses of infrastructure projects. To do this, Autocase calculates the TBL value (net societal benefit), which complements the Envision rating system. Net benefits are allocated to Envision categories. Autocase requires three types of inputs to perform its TBL calculations 
which are classified as design components, common components, and additional components. TBL value is calculated as net present value over the project life cycle. Pittsburgh's $2016 \mathrm{draft}$ green first plan used Autocase for TBL calculations (PWSA 2016).

\section{Conclusions}

In relation to infrastructure projects, green first does not mean green only. Green stormwater infrastructure is not a panacea. GSI is a new technology which offers both challenges and opportunities. Therefore the green first approach for solving wet weather problems should be implemented with caution. Using lessons learned, cities can minimize the GSI challenges and maximize the opportunities for GSI to be a successful wet weather overflow solution. Comparing green and gray solutions using objectively calculated TBL values based on hydraulic performance and life cycle cost is essential for the justification of a green first approach. The TBL value of a green first approach can be increased by incorporating blue and gray infrastructure (i.e. hybrid solutions). The wet weather industry has recently developed the software tools for performing green first analysis tasks. The number of published case studies in the literature comparing green and gray hydraulic performance, life cycle cost, and TBL for a particular sewershed and the same level of control remains small.

\section{References}

3RWW (3 Rivers Wet Weather). 2013. 3 Rivers Wet Weather. Pittsburgh, PA: 3RWW. http://www.3riverswetweather.org/green/green-solutions

ALCOSAN (Allegheny County Sanitary Authority). 2012. Draft Wet Weather Plan. Pittsburgh, PA: Allegheny County Sanitary Authority.

http://www.alcosan.org/WetWeatherlssues/ALCOSANDraftWetWeatherPlan/DraftWWPFullDocument/tabid/176/ Default.aspx

City of Atlanta. 2017. West Area CSO Tunnel. Atlanta, GA: City of Atlanta Department of Watershed Management. http://www.atlantawatershed.org/projects/completed/ west-area-cso-tunnel/

Driscoll, C. T., C. G. Eger, D. G. Chandler, C. I. Davidson, B. K. Roodsari, C. D. Flynn, K. F. Lambert, N. D. Bettez and P. M. Groffman. 2015. Green Infrastructure: Lessons from Science and Practice. Millbrook, NY: Cary Institute of Environmental Studies-Syracuse University-Science Policy Exchange. https://s3.amazonaws.com/nyclimatescience.org/gi_report_surdna_6_29_15_final.pdf

Lennon, L, U. Shamsi, A. Igwe, J. Schombert and J. Maslanik. 2013. "Green Infrastructure Opportunities in Gray Wet Weather Plans." In Proceedings of the Water Environment Federation, Collection Systems 2013, 274-88. Alexandria, VA: Water Environment Federation.

https://doi.org/10.2175/193864713813504520
Moore, D. 2015. “Pittsburgh, Cleveland: Vastly Different Approaches to Wastewater." Pittsburgh, PA: Pittsburgh Post-Gazette, 2015-04-05.

https://www.questia.com/newspaper/1P2-38188680/pittsburgh-cleveland-vastly-different-approaches

Parker, J. 2017. A Suggestion for a Better Infrastructure Report Card. New York: Impact Infrastructure.

https://blog.autocase.com/blog/2017/03/10/a-suggestionfor-a-better-infrastructure-report-card/

Pica, L. and U. M. Shamsi. 2017. "The State of CSO Control." Paper presented at The Technology Transfer Seminar, New Jersey Water Environment Association, September 11-14, 2017.

PWSA (Pittsburgh Water and Sewer Authority). 2016. The Green First Plan: A City-Wide Green Infrastructure Assessment (Draft). Pittsburgh, PA: Pittsburgh Water and Sewer Authority. http://apps.pittsburghpa.gov/pwsa/PWSA_City_Wide_Report_11-10-16_DRAFT.pdf

Seattle Magazine. 2011. “Worst of 2011." Seattle, WA: Tiger Oak Media. http://www.seattlemag.com/article/worst-2011

Shamsi, U. M. 2011. “Modeling to Quantify the LID Benefits for CSO Reduction." Presented at 5th EWRI National Low Impact Development Conference and Low Impact Development Symposium: Greening the Urban Environment, Philadelphia, September 25-28, 2011. Reston, VA: American Society of Civil Engineers. https://doi.org/10.1061/9780784413883.015

Shamsi, U. M. and D. Barron. 2015. “Green CSO Solutions: Opportunities and Challenges." Paper presented at PennTec 2015: 87th Annual Conference and Exhibition of the Pennsylvania Water Environment Association, Lancaster, PA, June 1, 2015.

Shamsi, U. M., B. Gamble and J. Koran. 2016. "Cincinnati's SWMM Model: A Journey Through Time." Journal of Water Management Modeling C398. https://doi.org/10.14796/JWMM.298

Shamsi, U. M., J. Schombert and L. Lennon. 2013. "SUSTAIN Applications for Mapping and Modeling Green Stormwater Infrastructure." Journal of Water Management Modeling C379. https://doi.org/10.14796/JWMM.C379

Stiffler, L. 2011. “Ballard Rain Gardens: A Green Solution Gone Wrong." Seattle, WA: InvestigateWest, 2011-04-23. http://invw.org/2011/04/23/rain-gardens-not-working-outin-ballard/

Urbonas, B., C. C. Olson, K. MacKenzie and J. Guo. 2013. “BMP Economics and Sizing." Journal of Water Management Modeling R246-19. https://doi.org/10.14796/JWMM.R246-19

USEPA (U.S. Environmental Protection Agency). 2013. SUSTAINSystem for Urban Stormwater Treatment and Analysis IntegratioN Model. Washington, DC: U. S. Environmental Protection Agency. www.epa.gov/nrmrl/wswrd/wq/models/sustain. 
USEPA (U.S. Environmental Protection Agency). 2017. Green Infrastructure Cost-Benefit Resources. Washington, DC: U.S. Environmental Protection Agency.

https://www.epa.gov/green-infrastructure/green-infrastructure-cost-benefit-resources
Wikipedia. 2017. Whole-Life Cost. https://en.wikipedia.org/wiki/ Whole-life_cost 